\title{
Erratum to: How does long-term parenteral nutrition impact the bone mineral status of children with intestinal failure?
}

Antonella Diamanti - Carla Bizzarri - Maria Sole Basso - Manuela Gambarara •

Marco Cappa · Antonella Daniele $\cdot$ Cristian Noto $\cdot$ Massimo Castro

Published online: 5 March 2010

(C) The Japanese Society for Bone and Mineral Research and Springer 2010

Erratum to: J Bone Miner Metab

DOI 10.1007/s00774-009-0140-0

The correct name of the second author should be given as

Carla Bizzarri, not Claudia Bizzarri.

The online version of the original article can be found under doi:10.1007/s00774-009-0140-0.

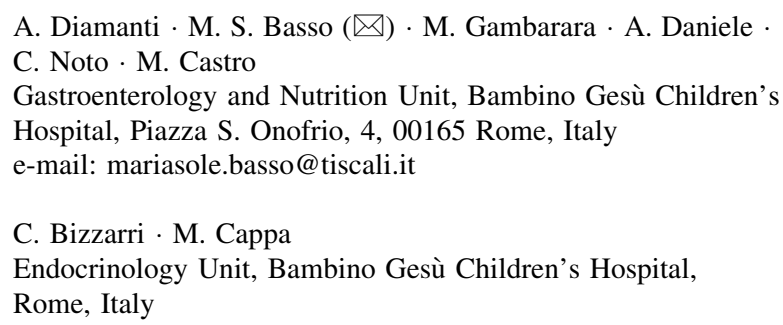

